\section{PEER-REVIEWED ARTICLE}

Food Protection Trends, Vol 41, No. 3, p. 266-273 Copyright 2021, International Association for Food Protection 2900 100th Street, Suite 309, Des Moines, IA 50322-3855
Bridget J. Perry, ${ }^{1}$ Angela M. Shaw, ${ }^{2 *}$

Arlene E. Enderton, ${ }^{3}$ Shannon S. Coleman ${ }^{4}$ and Ellen E. Johnsen ${ }^{5}$

1,2.4.5 Dept. of Food Science and Human Nutrition, lowa State University, 2312 Food Sciences Bldg., 536 Farm House Lane, Ames, IA 50011-1057, USA

lowa State University Extension and Outreach Farm, Food, and Enterprise Development, lowa State University, 2526 N. Loop Drive, Suite 2430, Ames, IA 50010, USA

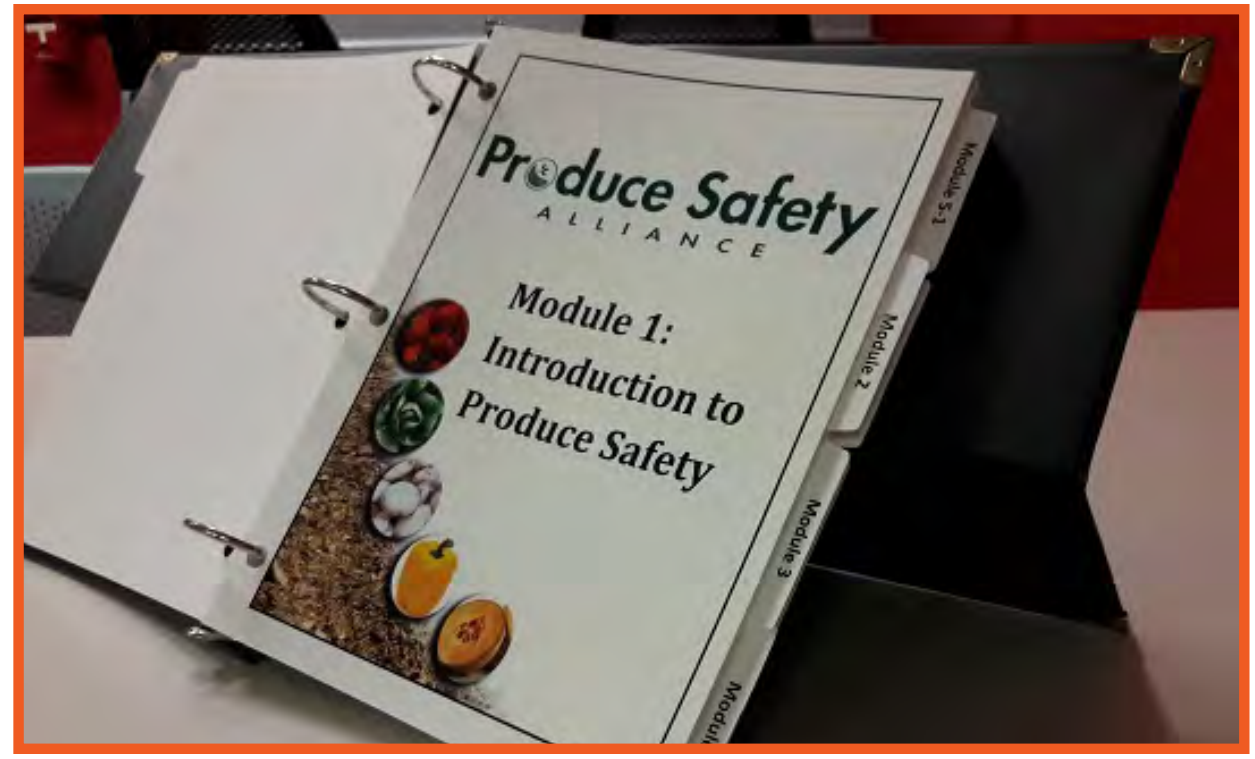

\title{
North Central Region Produce Grower Training: Pretest and Posttest Knowledge Change and Produce Safety Behavior Assessment
}

\section{ABSTRAGT}

The objective of this study was to determine whether there was knowledge gain and behavioral change by produce growers within the North Central Region (NCR) of the United States who participated in the Produce Safety Alliance (PSA) Grower Training. Over a 2-year period, the 25-question knowledge assessment was administered to participants $(n=2,286)$ at the beginning and at the end of each 8-h training to measure knowledge gain. Behavioral change was assessed using a survey 12 months after the training. Average scores measuring the participants' knowledge increased significantly from pretest [16.1 of 25, 68\%) to posttest [20.0 of 25, $80 \%)(P=0.001)$. On average, participants in trainings not targeting special populations $(n=1,735)$ improved their scores more than participants in trainings for special populations $(n=509)(P=0.001)$. Of growers, 199 (72\%) of 276 who responded to the follow-up survey indicated that they had made a behavioral change, such as writing or modifying farm food safety plans $(n=$ 108), implementing different training for employees on food safety ( $n=108$ ), and modifying food record-keeping systems ( $n=98$ ). The results indicate that behavioral change did not correlate with knowledge gain. Educational materials should be developed to encourage both knowledge and behavioral change.

\section{INTRODUCTION}

The Produce Safety Rule (PSR) is one of seven rules written under the Food Safety Modernization Act (FSMA) $(25,26)$. The PSR is the first federal mandate of sciencebased minimum standards for the growing, harvesting, packing, and holding of produce for human consumption (26). Standards within the rule include six key requirements: agriculture water; biological soil amendments; sprouts; domestic and wild animals; worker training and health and hygiene; and equipment, tools, and buildings (25). One of the requirements of the FSMA PSR is that at least one member of qualifying farm entities must take a U.S. Food and Drug Administration (FDA)-approved produce safety course, such as the Produce Safety Alliance (PSA) Grower Training (17). Extension educators, fresh produce 
commodity organizations, and various state departments of agriculture are utilizing the PSA Grower Training to help the produce industry meet the educational requirements in the FSMA PSR.

Pre- and posttest knowledge assessments are standard tools used to evaluate the effectiveness and impact of extension programs to measure how much participants learned through the program and their understanding of presented materials $(1,22)$. Pre- and posttest assessments were used in studies to assess the culture of fresh produce safety within a leafy greenproducing community and to assess the current knowledge and attitudes of small-scale growers related to good agricultural practices and good manufacturing practices $(12,13,20)$.

This form of assessment has also been utilized to evaluate many types of food safety education. Specifically, Nayak et al. (2015) found that pretest scores were accurate measures of participants' beginning knowledge in good agricultural practices workshops (12). Furthermore, in targeted food safety workshops, Dittmar et al. (2014) found that the use of pre- and posttest knowledge assessments were a useful tool to show participants' knowledge gain during courses (5).

Researchers have found that knowledge gain alone is associated with limited behavioral change and that an increase in knowledge can influence individuals to make more informed choices, which may or may not result in a behavioral change (10). Pratt and Bowman (2008) suggest that the likelihood of knowledge being incorporated by individuals into their lives increases when specific knowledge and skills are identified and supported; this creates the foundation for new behaviors (15). Nayak et al. (2015) utilized the extension framework of Rockwell and Bennett's seven hierarchical steps to explain behavioral change among individuals who participate in programming (12). The authors mentioned that this is more likely to occur after their knowledge, attitudes, skills, aspirations, and intentions have changed.

The objective of this study is to determine to what extent participation in the FDA-approved PSA Grower Training promoted knowledge change among produce growers from
10 states within the North Central Region (NCR) of the United States over 2 years and how this knowledge change translated into behavioral change 12 months after the training, measured through a self-reported survey.

\section{MATERIALS AND METHODS}

\section{Knowledge assessment tool development}

The knowledge assessment tool was developed and piloted by Dr. Catherine Shoulders at the University of Arkansas (21) and is at a 9.5 reading level according to Microsoft Word 2016 readability statistics and Flesch-Kincaid Grade Level. The exam questions were validated using Cronbach's alpha, which yielded internal consistency and face and content validity (21). Divergent validity was established through pilot tests with growers $(n=23)$ and graduate students $(n=$ 15) (21). Table 1 lists which knowledge assessment questions relate to which PSA Grower Training module. Examples of the type of questions asked and the modules they relate to include "Which of the following options can be used as an indicator of fecal contamination of a water source?" (module 5, Agricultural Water: Part I Production Water; Part II Postharvest Water) and "Which of the following has the responsibility of developing a Farm Food Safety Plan?" (module 7, How to Develop a Farm Food Safety Plan). Each question was assigned 1 point, which required the module scores to be rescaled to a 5-point scale to make comparisons across modules. This knowledge assessment tool is in ongoing use as a research tool and, thus, is not shared with the general public. Iowa State University approved the use of the knowledge assessment tool by the Office for Responsible Research, Human Research Institutional Review Board (no. 18-004) (14).

Administration of pretest and posttest knowledge assessment

Each PSA Grower Training Course was administered over $8 \mathrm{~h}$, in person. The knowledge assessment was administered before (pretest) and after (posttest) the training as a paper copy in eight NCR states in year 1 (October 2017 to

\section{TABLE 1. Knowledge assessment questions linked to specific Produce Safety Alliance}

(PSA) Grower Training modules

\begin{tabular}{l|l} 
Knowledge assessment questions & PSA Grower Training module \\
\hline $1,2,3,4$, and 18 & Module 1: Introduction to Produce Safety \\
\hline 5 and 6 & Module 2: Worker Health, Hygiene, and Training \\
\hline $7,8,9$, and 10 & Module 3: Soil Amendments \\
\hline $11,12,13$, and 14 & Module 4: Wildlife, Domesticated Animals, and Land Use \\
\hline 15,16, and 17 & Module 5: Agricultural Water: Part I Production Water; Part II Postharvest Water \\
\hline 19,20, and 21 & Module 6: Postharvest Handling and Sanitation \\
\hline $22,23,24$, and 25 & Module 7: How to Develop a Farm Food Safety Plan \\
\hline
\end{tabular}


May 2018): Indiana, Iowa, Kansas, Minnesota, Missouri, Nebraska, South Dakota, and Wisconsin. In year 2 (October 2018 to May 2019), it was administered in 10 NCR states (Illinois, Indiana, Iowa, Kansas, Michigan, Minnesota, Missouri, Nebraska, South Dakota, and Wisconsin). In year 2 , trainers provided a cover sheet along with the knowledge assessment, which included the name of the trainer, number of participants, training location, and date, along with the population served. The populations were defined as follows: no special populations (traditional grower populations), Plain growers (Amish and Mennonite), beginning farmers, local food growers, military veterans, minority farmers, non-English and limited English proficiency (this dataset includes Spanish-speaking populations only), and other special population. The data regarding special populations were not based on self-reported demographic information from participants but on whether the trainer advertised the training as being for a specific type of grower. In year 1 , trainers were not asked to complete a cover sheet, but evaluators later collected data via email about special populations served by the trainings.

\section{Twelve-month behavioral change follow-up survey}

Follow-up surveys were administered electronically using Qualtrics for those who use technology and in paper form for participants who do not use technology. The only state modification was in Wisconsin, where paper copies were provided to all participants along with electronic invitations to those who use technology. One or two reminders were sent to those who use technology (this varied by state), whereas no reminders were sent to those who received paper copies. During year 1, food safety specialists from Illinois, Indiana, Iowa, Kansas, Michigan, Missouri, Nebraska, South Dakota, and Wisconsin administered the survey to participants approximately 12 months (October 2017 through May 2018) after their participation in the PSA Grower Trainings, to measure behavior change. In year 2, the surveys were sent to participants between December
2018 and March 2019, approximately 12 months after their training. Of the 1,436 individuals invited to take the survey, 364 responses were received, for a $25.3 \%$ response rate.

\section{Statistical analysis}

Knowledge assessment data were entered into Qualtrics from the 40 trainings that were collected in year 1 ( $n=$ 860 participants) and from the 93 trainings ( $n=1,745$ participants) that were collected in year 2. Pretests and posttests were matched using a unique identification number written on each quiz and analyzed using IBM SPSS Statistics 26. The inclusion criteria for the analysis required that both pretest and posttest be fully completed. Pretests and posttests that did not meet the inclusion criteria were excluded, using the select cases function. Pretest and posttest scores were calculated and module scores were tallied, with 1 point assigned to each question. Module scores were then rescaled to a 5-point scale so that scores could be compared across modules. Paired sample $t$-tests (comparing average pretest and posttest), independent samples $t$-tests (across years and special populations), and descriptive statistics such as the mean were calculated. For the 12-month follow-up survey, analysis was performed using IBM SPSS Statistics 25 with descriptive statistics.

\section{RESULTS}

A total of 2,605 knowledge assessment responses were received over 2 years: 860 paper copies from year 1 and 1,745 from year 2 (Table 2 for population analysis). The number of responses that met the inclusion criteria was 2,286 (year $1=$ 767 and year $2=1,519)$. The year 1 average total pretest score was $16.3(65 \%)$ of 25 , whereas the year 2 average total pretest score was $16.0(64 \%)$ of 25 . The difference in these scores was not statistically significant $(P=0.058)$. This indicates that growers' incoming knowledge was the same in years 1 and 2 . The average of the 2 -year total pretest and posttest scores $(n=2,286)$ was $16.1(64 \%)$ of 25 and $20.0(80 \%)$ of 25 , respectively $(P=0.001)$.

TABLE 2. Pre- and posttest knowledge assessment score of growers taking the Produce Safety Alliance Grower Training between 2016 and 2019 in the North Central region of the United States

\begin{tabular}{l|c|cc} 
Population & Pretest score & Posttest score & Significance \\
\hline All populations $(n=2,286)$ & $16.10 / 25$ & $20.00 / 25$ & $P=0.001$ \\
\hline Traditional population $(n=1,713)$ & $16.56 / 25$ & $20.56 / 25$ & $P=0.001$ \\
\hline Plain growers $(n=284)$ & $14.29 / 25$ & $17.92 / 25$ & $P=0.001$ \\
\hline Minority farmers $(n=19)$ & $15.31 / 25$ & $19.05 / 25$ & $P=0.001$ \\
\hline Non-English speaking or limited English proficiency $(n=22)$ & $10.09 / 25$ & $11.45 / 25$ & $P=0.035$ \\
\hline Other special population $(n=182)$ & $15.98 / 25$ & $19.74 / 25$ & $P=0.001$ \\
\hline
\end{tabular}


Trainings held for traditional grower populations reached 1,735 individuals (year $1=648$ and year $2=1,087$ ), whereas trainings targeting special populations reached 509 (year 1 $=119$ and year $2=390)$. There were higher pretest scores for traditional grower trainings (16.6 points on a 25 -point scale) than for special population trainings (14.8 points) $(P=0.001)$. This indicates that individuals who attended trainings not targeting a special population had a higher incoming knowledge of the PSR than did special populations, on average. Similarly, on average, growers participating in training that did not target special populations also had a higher total score change from pretest to posttest (4.0 on a 25-point scale) than did special populations (3.6 on a 25-point scale $)(P=0.005)$. When the pretest versus posttest for all the special population training populations was compared, there was a difference $(P=0.001)$, indicating knowledge gain. When special population trainings were separated by specific population, participants in trainings for plain growers averaged a total pretest score of 14.3 (57\%) and total posttest score of 17.9 (72\%), with a total score change of $3.6(P=0.001)$; participants in trainings for minority farmers averaged a total pretest score of $15.2(61 \%)$ and posttest score of $19.1(76 \%)$, with a total score change of $3.8(P=0.001)$; participants in trainings for non-English and limited English proficiency growers averaged a total pretest score of 10.1 (40\%) and an average total posttest score of 11.5 (46\%), with a total score change of $1.36(P=0.035)$; and participants in trainings for other special populations averaged a total pretest score of 16.0 (64\%) and posttest score of 19.7 (79\%), with a total score change of $3.8(P=0.001)$.
When all training populations were combined along with both years, participants scored the highest on both the pretest and posttest in module 1 (Introduction to Produce Safety), module 2 (Worker Health, Hygiene and Training), and module 3 (Soil Amendments) (Fig. 1), which, in turn, provided the lowest increase in score (module 2 increasing by 0.1 , module 3 by 0.2 , and module 1 by 0.6 on a 5 -point scale). This indicates that participants had higher knowledge of these three modules than of the other modules prior to taking the training. Participants scored the lowest on both pretests and posttests in module 4 (Wildlife, Domesticated Animals, and Land Use), module 5 (Agricultural Water), module 6 (Postharvest Handling and Sanitation), and module 7 (How to Develop a Farm Food Safety Plan) consistently across both years. Whereas participants' scores were the lowest in those modules, their scores improved the most from pretest to posttest on these modules. Analysis of specific questions in the knowledge assessment tool identified that questions $11,13,17,22$, and 24 (modules 4,5 , and 7 ) were particularly hard for respondents to answer correctly in both years (Table 3).

The 12-month behavioral change survey revealed that 199 (72\%) of 276 growers responding to the survey made a change on their farms between the time they took the PSA Grower Training and the time when they took the survey. Most common changes included implementing new or different training for employees on food safety and hygiene protocols (44\%), writing, completing, or modifying farm food safety plans (40\%), implementing new or different practices for monitoring on-farm facilities (37\%), and

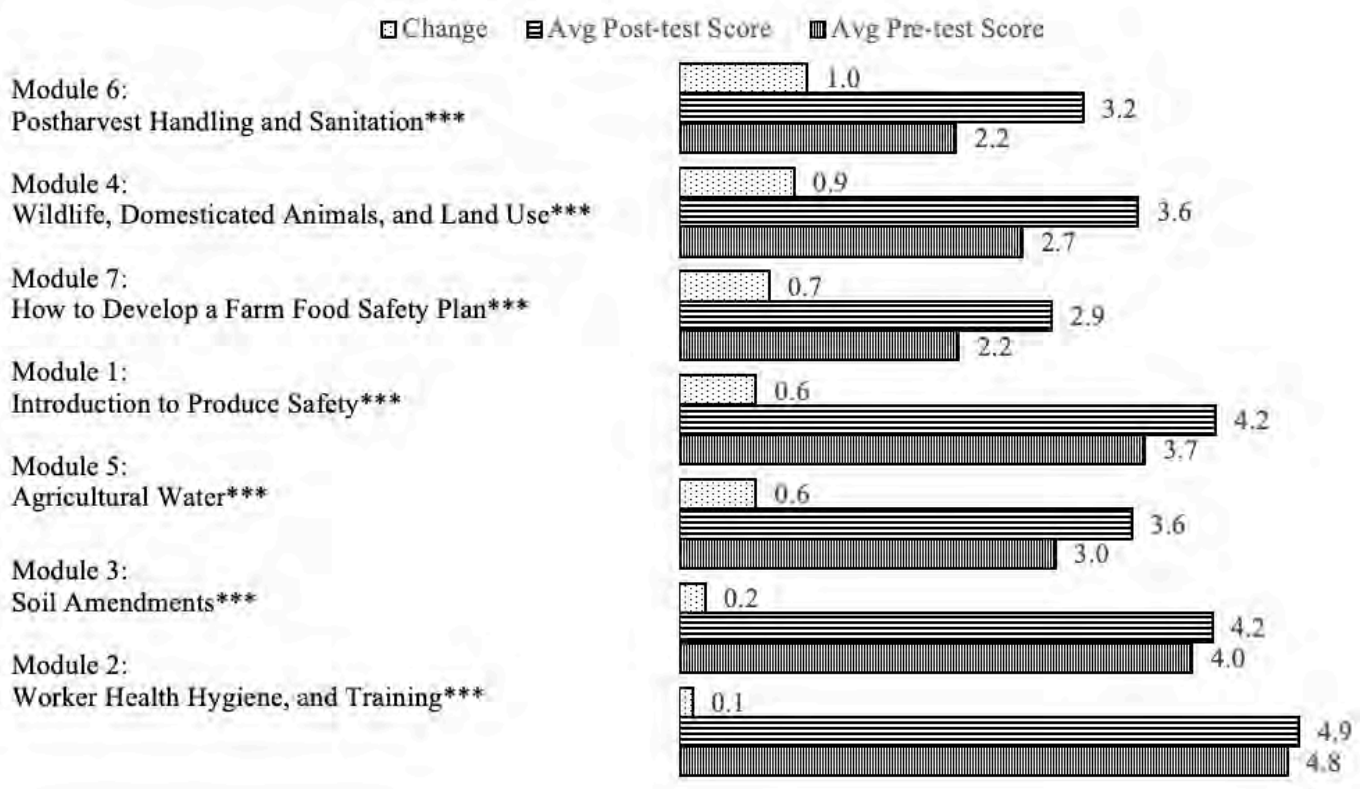

FIGURE 1: Average total module score and the total change in pretest to posttest score on a 5-point scale. *** Significant difference between pretest and posttest using an alpha of 0.05 . 


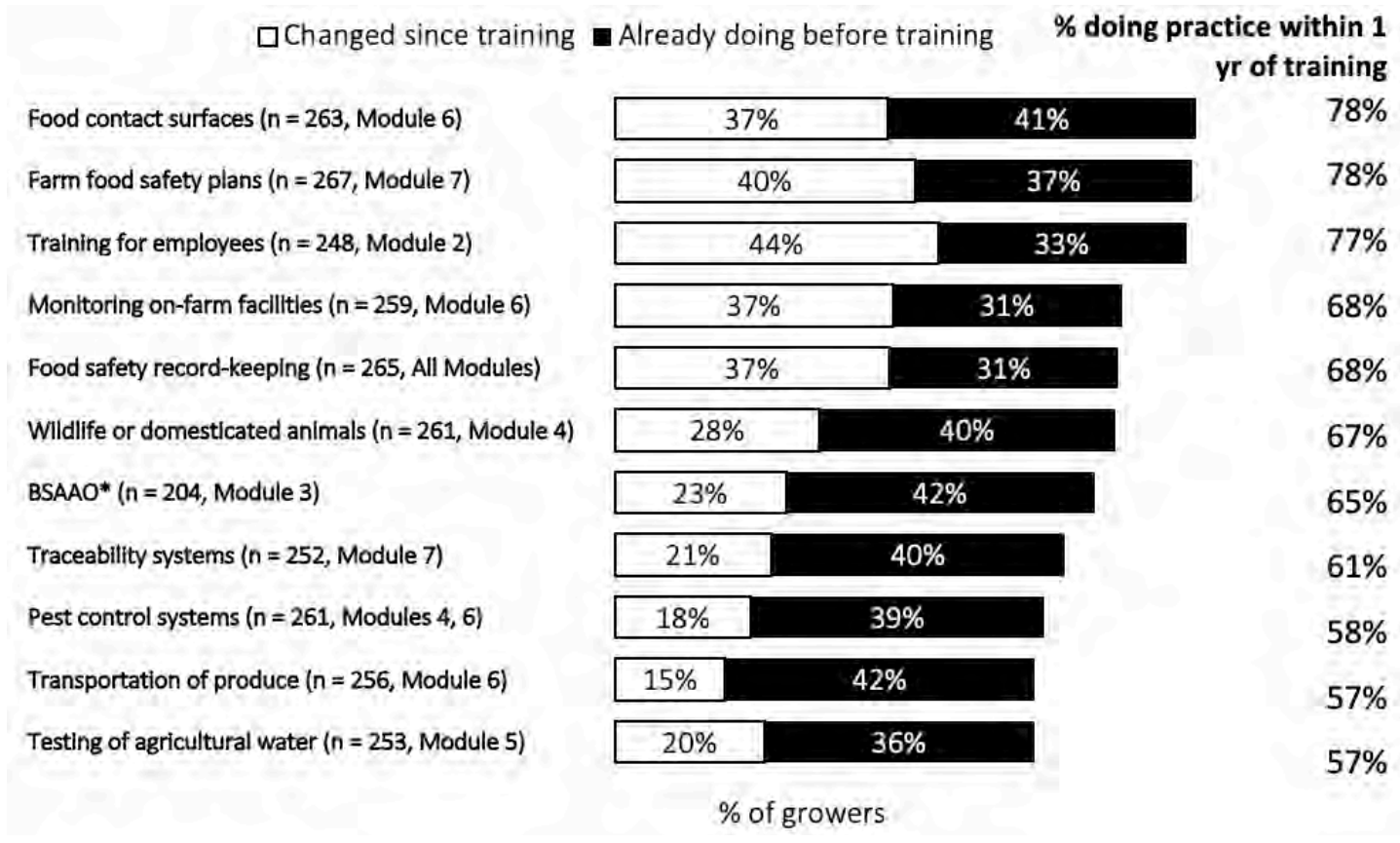

FIGURE 2. Percent of growers that made some sort of food safety practice change since completing the PSA Grower Training. *BSAAO means biological soil amendments of animal origin.

creating or modifying food record-keeping systems (37\%). Least common changes included implementing new or different methods for transportation of produce (15\%), new or different pest control systems (18\%), and new or different testing of agricultural water for generic E. coli (20\%). The 12-month behavioral follow-up survey also indicated that $33 \%$ of respondents were already implementing training for employees before the training and that $44 \%$ made a change to their practice after training (Fig. 2). The survey also found that $42 \%$ of participants were implementing practices related to transportation of produce before the training and that $15 \%$ made a change after receiving training.

\section{DISCUSSION}

Research has shown that participants' knowledge may increase on specific topics; however, modifications in their attitudes, improvement in their skills, and changes in their aspirations or intentions are required to change participants' behaviors or practices (12). The results from this study indicated that growers surveyed were able to acquire knowledge and change behaviors following their PSA Grower Training. This also showed that the amount of knowledge change varied between traditional populations and all the special populations in the study. Strohbehn et al. (2018) suggested that the complexity of the PSR, the wording of questions, and language barriers may have been causes for lower scores of special populations (23). A barrier identified with the knowledge assessment tool utilized in this study was the reading grade level of 9.5. Although this survey tool was piloted with a variety of grower populations, special population growers may be challenged by the high reading level of the questions, specifically the non-English and limited English proficiency populations. Munro (2017) notes that many Amish populations attend school until the eighth grade, and a study conducted by Bergefurd (2011) found that $94 \%$ of Amish and Mennonite produce auction farmers in Ohio had less than a 12th grade education (2, 11). The Pew Research Center has also found that $75 \%$ of individuals in the United States who identify as Hispanic and who do not speak English as a first language have less than a high school education (7). Results from this study showed that non-English speaking and limited English proficiency populations, followed by plain growers, had the lowest scores of all the populations. To accommodate the language barrier, educators in Michigan held two trainings for non-English speaking populations in Spanish and the knowledge assessment was written in Spanish. Translation into native languages has been shown to be important in making training examples more culturally relevant for diverse audiences $(19,23)$. Additional suggestions from this study highlighted the need for visual-based educational materials that are appropriate for diverse populations. If the visual-based educational materials are developed, it is important to ensure that the materials are appropriate for the specific populations. Research also indicated that the use of various types of training methods, such as storytelling, are 
extremely important when training an audience whose native language is not English (9). The authors suggest that the use of illustrative resources, such as videos, charts, or pictures, can convey information without language use. The authors also suggest that trainings limit the use of food safety jargon (words such as bacteria, contamination, and hygiene) by replacing them with terms that are more familiar to produce workers (such as germs) (9).

Low posttest scores for module 4 (Wildlife, Domesticated Animals, and Land Use) and module 6 (Postharvest Handling and Sanitation) are of particular concern because animals and sanitation practices have been linked to produce outbreaks. For example, deer feces in the growing environment were the source of contamination in the 2011 E. coli $\mathrm{O} 157: \mathrm{H} 7$ outbreak linked to strawberries in Oregon (8). The importance of postharvest handling and sanitation was reported in the 2011 multistate outbreak of Listeria in cantaloupe (24). In the final FDA environmental assessment report for this outbreak, FDA reported that the facility had recently acquired and installed equipment previously used for another raw agricultural commodity (potatoes) and that this equipment could not be easily cleaned and sanitized. In addition, the facility's floor was constructed in a way that prevented adequate cleaning and sanitizing.

Within 1 year of completing the PSA Grower Training Course, $67 \%$ of growers made a food safety practice change related to wildlife or domesticated animals. If there is reasonable probability that animal intrusion will contaminate produce, $\$ 112.83(\mathrm{a})$ of the FSMA PSR requires that those areas used for growing covered produce be monitored as needed during the growing season and immediately prior to harvest. Practices commonly used to conserve natural resources and encourage wildlife can appear to conflict with on-farm food safety practices. Comanagement among wildlife, the environment, and a produce farm provides a way to address complex farm management needs through a mutually beneficial approach. Many physical decoys and chemical applications used to deter or repel wildlife work only temporarily, after which the wildlife return. Although the FSMA PSR is clear in its mandate that no produce that has been in contact with animal fecal matter is to be harvested for human consumption, the FSMA PSR, as of May 2020, lacks final ruling on the application standards for untreated biological soil amendments of animal origin (BSAAO) (28). The FDA has delayed rule enforcement until a risk assessment and additional research about the effectiveness of integrating appropriate application intervals to protect public health have been conducted (27). To help the FDA develop appropriate guidance on BSAAO, Soil Summits were held in Geneva, NY (March 2017), Houston, TX (December 2017), and Atlanta, GA (January 2018 and September 2019) (18). The produce industry provided information and insights to inform the process of clarifying the reserved part of the PSR regarding application intervals for untreated BSAAO (18).
This process is to ensure that FDA has a good knowledge of how untreated BSAAO are used on produce farms and of the issues growers face in implementing practices to reduce risks (27). A fact sheet was developed by FDA in 2019 to clarify FDA's definition of BSAAO, how and when they can be applied, and where to find relevant requirements within the PSR. In addition, a stand-alone course about BSAAO was held in Altoona, IA, in fall 2019 (27).

The low posttest scores for module 6 (Postharvest Handling and Sanitation) provide evidence that more education is needed about this topic. The importance of postharvest handling and sanitation for plant disease control has been researched for decades among the horticulture community. Boyette et al. (1993) explain that "Pathogens brought into the packing house along with the produce will contaminate all working surfaces quickly. Decay-causing organisms attached to the tank walls, grading belts, brushes, and other surfaces can remain viable for months" (4). The authors of this paper suggest that time, labor, monetary investment, infrastructure, and equipment design are barriers to improving postharvest handling and sanitation, as observed during human food inspections under the Preventive Controls for Human Foods Rule. In a report by FDA in October 2019, in the United States there were 516 full-scope FSMA Human Food Preventive Control Inspections, which resulted in 157 no action indicated (meaning no action required), 172 voluntary action indicated, and 64 official action indicated. Three of the five most frequent citations related to food handling and sanitation practices were (i) 21 CFR 117.165(b) (Sanitation Controls Verification Procedures: Establish \& Implement);

(ii) 21 CFR 117.145(a) (Process Controls; Monitoring Procedures: Establish \& Implement); and (iii) 21 CFR 117.145(a) (Sanitation Controls Monitoring Procedures: Establish \& Implement) (6). Within the postharvest setting, postharvest monitoring and sanitation to prevent and eliminate crop disease are well practiced. Still, foodborne pathogens do not manifest in physical crop damage, making it harder for growers to prioritize food safety in their daily routine. The self-reported behavioral change data indicate that $37 \%$ of participants are implementing new or different practices for monitoring on-farm facilities.

On average, respondents' lowest pretest and posttest scores were for module 7 (How to Develop a Farm Food Safety Plan). The module contained two of the top five most missed questions (22 and 24, Table 3). Confusion over question 22 may have stemmed from the fact that the PSA Grower Training has an entire module that covers how to develop a farm food safety plan but the FSMA PSR does not require that a farm have a written food safety plan (16). It is suggested, however, that having a written plan can help growers become more organized and focused when it comes to produce safety and can help with preparing for buyer requirements and third-party audits (16). The behavioral 
TABLE 3. Top five problem questions from the Produce Safety Allance Grower Training module and the percent that correctly answered the questions in both years

\begin{tabular}{l|l|c|c}
\hline Question no. and corresponding module & Question & $\begin{array}{c}\text { Pretest } \\
\% \text { correct }\end{array}$ & $\begin{array}{c}\text { Posttest } \\
\% \text { correct }\end{array}$ \\
\hline $\begin{array}{l}11 \text { (Module 4: Wild, Domestic Animals, and } \\
\text { Land Use) }\end{array}$ & $\begin{array}{l}\text { Comanagement refers to the balance between which } \\
\text { two factors? }\end{array}$ & 49 & 77 \\
\hline $\begin{array}{l}13 \text { (Module 4: Wild, Domestic Animals, and } \\
\text { Land Use) }\end{array}$ & $\begin{array}{l}\text { Which of the following choices is least likely to reduce } \\
\text { your property's wildlife population? }\end{array}$ & 38 & 58 \\
\hline $\begin{array}{l}17 \text { (Module 5: Agriculture Water Part I: } \\
\text { Production Water; Part II Postharvest Water) }\end{array}$ & $\begin{array}{l}\text { Which of the following is used as an indicator of fecal } \\
\text { contamination of a water supply? }\end{array}$ & 24 & 73 \\
\hline $\begin{array}{l}22 \text { (Module 7: How to Develop a Farm Food } \\
\text { Safety Plan) }\end{array}$ & $\begin{array}{l}\text { Which of the following statements regarding Farm Food } \\
\text { Safety Plans is true? }\end{array}$ & 6 & 54 \\
\hline $\begin{array}{l}24 \text { (Module 7: How to Develop a Farm Food } \\
\text { Safety Plan) }\end{array}$ & $\begin{array}{l}\text { Which of the following records is required by the FSMA } \\
\text { Produce Safety Rule? }\end{array}$ & 33 & 39 \\
\hline
\end{tabular}

change results also indicated that $37 \%$ of participants wrote, completed, or modified their farm food safety plans after attending the course, which provides evidence of positive food safety change. This pattern, in which a low correct response rate is, nevertheless, accompanied by behavioral change, was also observed with question 24 (required records for PSR). In 2019, the Produce Safety Alliance developed a new document that highlights all the required records under the PSR for distribution (28). Many trainers have added this as a resource during their PSA Grower Trainings.

Another module that didn't show any knowledge change between pre- and posttest but that did show behavioral change was module 2 (Worker Health, Hygiene, and Training). The 12-month behavioral change results indicated that $33 \%$ of respondents were already implementing training for employees before the training and that $44 \%$ implemented this practice after training. The results of this study found behavioral change in many of the major PSR-required areas. Bihn et al. (2019) found that, among the various factors that motivate individuals to learn about food safety (3), the top four were (i) personal commitment to producing a safer product, (ii) reducing liability exposure, (iii) maintaining market access to meet buyer requirements, and (iv) meeting regulatory requirements of FSMA. Within this study the authors found that farmers with a written food safety plan ranked perceived barriers differently than those who did not have a food safety plan. Those with a plan ranked their top barriers as (i) time, (ii) financial resources, and (iii) liability; they were also less likely to select "greatly limiting" when rating levels of perceived barriers. Farmers without a written food safety plan, however, ranked their greatest perceived barriers as (i) financial resources, (ii) farm infrastructure, and (iii) time. These areas need to remain a focus of educators as they develop a new food safety curriculum and/or continue to deliver PSA Grower Trainings.

\section{CONCLUSIONS}

The goal of this study was to assess produce growers' knowledge change after attending the PSA Grower Training that was held between 2017 and 2019 in the NCR. Findings will be used to create educational materials and to gain insight on how to better conduct training so as to guide produce growers into compliance with the FSMA PSR. Findings suggest that trainers themselves may need more education on how to deliver practical training and resources and how to increase knowledge in specific portions of the FSMA PSR, which will reduce and/or eliminate confusion by the participants. The knowledge assessment is a standardized tool that has been used across every region in the United States; it can be a helpful tool to determine the future needs of the produce industry. Various educational resources such as fact sheets and guidance documents have been created by educators within the NCR to help guide the produce industry on the PSR to further increase pretest scores and behavioral change after the PSA Grower Training. This study provides evidence that the PSA Grower Training was effective at increasing the knowledge and behavioral change of the produce industry in 10 states in the NCR. This study also provides evidence that, whereas behavior change was observed after the training, it did not correlate neatly with the areas of knowledge gain. This confirms that knowledge is just one of many factors that contribute to behavior change. 


\section{ACKNOWLEDGMENTS}

This work was supported by the U.S. Department of Health and Human Services Food and Drug Administration [grant no. 1R01FD005685-01], the Food Safety Outreach Program [grant no. 2018-70020-28877] from the U.S. Department of Agriculture's National Institute of Food and Agriculture, and HATCH funding from project IOW0522. We acknowledge Dr. Catherine Shoulders, associate professor at the University of Arkansas, Dale Bumpers College of Agricultural, Food and Life Sciences, for her contribution to the development and piloting of the knowledge assessment survey. We also acknowledge all parties who provided data to this study. Specifically, we thank Southern Illinois University Carbondale (SIU), University of Illinois, Iowa State University, Kansas State University, Purdue University, Michigan State University, University of Minnesota, Lincoln University Missouri, University of Nebraska Lincoln, The Ohio State University, Purdue University, South Dakota State University, and University of Wisconsin-Madison for assisting with the data collection.

\section{REFERENCES}

1. Adedokun, O. A. 2018. Assessing instructional sensitivity using the pre-post difference index: a nontechnical tool for extension educators. J. Ext. 56:1-6.

2. Bergefurd, B. R. 2011. Assessing extension needs of Ohio's Amish and Mennonite produce auction farmers. Available at: https:// etd.ohiolink.edu/!etd.send_file?accession=0su1313512162\&disposition=inline. Accessed 20 December 2019.

3. Bihn, E. A., L. Pineda-Bermúdez, and L. Springer. 2019. Local food safety collaborative listening session report. Available at: http://localfoodsafety.org/wp-content/ uploads/sites/5/2019/10/LFSC-Listening-Session-Report-9-26-19.pdf. Accessed 20 December 2019

4. Boyette, M. D., D. F. Ritchie, S. J. Carballo, S. M. Blankenship, and D. C. Sanders. 1993. Chlorination and post-harvest disease control. J. Amer. Soc. Hortic. Sci. 3:395-400.

5. Dittmar, R. S., J. Anding, and S. Green. 2014 Improving food safety knowledge through an online training program. J. Ext. 52:1-5.

6. Food Safety Preventive Control Alliance. 2019. FSPCA 2019 annual conference in Burr Ridge Illinois. Available at: https://www. ifsh.iit.edu/sites/ifsh/files/departments/ fspca/pdfs/2019-FSPCA-Annual-Conference-PPT_2019-10-23_FINAL2.pdf. Accessed 7 February 2020.

7. Krogstad, J. M., R. Stepler, and M. H. Lopez. 2015. English proficiency on the rise among Latinos. U.S. born driving language changes. Available at: https://www.pewresearch.org/ hispanic/2015/05/12/english-proficiency-on-the-rise-among-latinos/. Accessed 7 February 2020.

8. Laidler, M. R., M. Tourdjman, G. L. Buser, T. Hostetler, K. K. Repp, R. Leman, M. Samadpour, and W. E. Keene. 2013 Escherichia coli O157:H7 infections associated with consumption of locally grown strawberries contaminated by deer. Clin. Infect. Dis. 57:1129-1134.

9. Mathiasen, L., K. Morley, B. Chapman, and D. Powell. 2012. Using a training video to improve agricultural workers' knowledge of on-farm food safety. J. Ext. 50:1-8.
10. Mullan, B., and C. Wong. 2010. Using the theory of planned behaviour to design a food hygiene intervention. Food Control 21:1524-1529.

11. Munro, C. D. 2017. Developing an Amish and Mennonite research registry in western Pennsylvania. Available at: http://d-scholarship. pitt.edu/31602/1/Christine_Munro_Thesis April2017.pdf. Accessed 13 December 2019

12. Nayak, R., D. Tobin, J. Thomson, R. B. Radhakrishna, and L. F. Laborde. 2015. Evaluation of on-farm food safety programming in Pennsylvania: implications for extension. J. Ext. 53:1-9.

13. Nolte, K. D., C. A. Sanchez, and J. M. Fonseca. 2011. Assessing the culture of fresh produce safety within a leafy green producing community. J. Ext. 49:1-7.

14. Office for Responsible Research Human, Institutional Review Board. 2019. Available at: https://www.compliance.iastate.edu/ committees/irb. Accessed 25 October 2019.

15. Pratt, C., and S. Bowman. 2008. Principles of effective behavior change: application to extension family educational programming. J. Ext. 46:1-4.

16. Produce Safety Alliance. 2019. Farm food safety plan writing resources. Available at: https://producesafetyalliance.cornell.edu/ resources/farm-food-safety-plan-writing resources/. Accessed 29 September 2020.

17. Produce Safety Alliance. 2019. Grower train ing course. Available at: https://producesafetyalliance.cornell.edu/training/grower-training-courses/. Accessed 7 February 2020

18. Produce Safety Alliance. 2019. Soil summits Available at: https://producesafetyalliance. cornell.edu/resources/soil-summits/. Accessed 7 February 2020.

19. Rajagopal, L. 2012. Use of visuals for food safety education of Spanish-speaking foodservice workers: a case study in Iowa. J. Ext. 50:1-13.

20. Shaw, A., C. L. Strohbehn, L. Naeve, P. Domoto, and L. Wilson. 2015. Systematic approach to food safety education on the farm. J. Ext. 53:1-7.
21. Shoulders, C. (University of Arkansas). 2020 Personal communication.

22. Spears, K., and M. Wilson. 2010. "I don't know" and multiple choice analysis of preand post-tests. J. Ext. 48:1-8.

23. Strohbehn, C. H., A. E. Enderton, A. M. Shaw, B. J. Perry, J. Overdiep, and L. Naeve. 2018. Determining what growers need to comply with the food safety modernization act produce safety rule. J. Ext. 56:1-10.

24. U.S. Food and Drug Administration. 2011. Environmental assessment: factors potentially contributing to the contamination of fresh whole cantaloupe implicated in a multi-state outbreak of listeriosis. Available at: http:// www.fda.gov/food/ recallsoutbreaksemergencies/outbreaks/ucm276247.htm. Accessed 7 February 2020.

25. U.S. Food and Drug Administration. 2017. FSMA final rule on produce safety. Available at: https://www.fda.gov/Food/GuidanceRegulation/FSMA/ucm33414.htm. Accessed 7 February 2020.

26. U.S. Food and Drug Administration. 2018. Background on the FDA food safety modernization act (FSMA). Available at: https:// www.fda.gov/food/food-safety-modernization-act-fsma/background-fda-food-safety-modernization-act fsma\#: : :text=This $\% 20$ is $\% 20$ a $\% 20$ significant $\% 20$ public,by $\% 20$ President\%20Obama\%20on\%20Jan.\&text=It\%20 enables\%20FDA\%20to\%20focus,to\%20problems\%20after\%20they\%20occur. Accessed 29 September 2020.

27. U.S. Food and Drug Administration. 2019 FDA fact sheet. Biological soil amendments of animal origin (BSAAO). Available at: https://www.fda.gov/media/114775/download. Accessed 7 February 2020.

28. Woods, K., D. Pahl, D. Stoeckel, B. Fick, G. Wall, and E. A. Bihn. 2020. Records required by the FSMA produce safety rule. Available at: https://producesafetyalliance. cornell.edu/sites/producesafetyalliance.cornell.edu/files/shared/documents/RecordsRequired-by-the-FSMA-PSR.pdf. Accessed 9 September 2020 